\title{
Pupils' knowledge and spoken literary response beyond polite meaningless words: studying Yeats' 'Easter, 1916'.
}

\author{
John Gordon \\ Correspondence: john.gordon@uea.ac.uk
}

\begin{abstract}
This paper presents research exploring the knowledge pupils bring to texts introduced to them for literary study, how they share knowledge through talk, and how it is elicited by the teacher in the course of an English lesson. It sets discussion in a context where new examination requirements diminish the relevance of social, cultural and historical knowledge in literary response, while curricular detail asserts the capacity of literature to support the cultural, emotional, intellectual, social and spiritual development of young people. Transcripts of classroom discussion of 'Easter, 1916' by W.B.Yeats show where and how pupils' deploy their own knowledge in interpretive work, and subtle techniques used by the teacher to elicit knowledge sharing. The data suggests the fallacy of decontextualized analysis of literature, and the significance of shared knowledge in communal spoken literary response.
\end{abstract}

\section{Introduction: polite meaningless words?}

This article considers conversation around literature in secondary phase classrooms, framed by the conventions of literary study in the discipline named 'English' in the National Curriculum for England and Wales. The 2014 revised curriculum documents (Department for Education, 2014:3) describe the 'pre-eminent place' of English 'in education and in society', further stating that 'high-quality education in English will teach pupils to speak and write fluently so that they can communicate their ideas and emotions to others and through their reading and listening, others can communicate with them'. Literary study is positioned as the main vehicle for achieving these aims, as it is 'through reading in particular [that] pupils have a chance to develop culturally, emotionally, intellectually, socially and spiritually'. Of additional note in terms of social-constructivist accounts of learning - where literature is to be considered through talk - is this phrase: 'reading also enables pupils both to acquire knowledge and to build on what they already know'. Pupils' knowledge relevant to a text introduced to them for literary study is my concern here, and how that knowledge comes to be shared through talk by pupils, or elicited by the teacher, in the course of an English lesson.

In the early months of next year Ireland will mark the centenary of the Easter Rising. Sometimes known as the Easter Rebellion, its protagonists aimed to establish an independent Irish republic to free the country of British rule. Their efforts across late April 1916 failed and most of the leaders were executed, though the momentum of the rebellion eventually led to Irish independence in early 1919. The poem 'Easter, 1916' by W.B.Yeats describes these events and the martyrdom of the rebels following their execution. It is a poem that has interested me for many years, first in itself and then, pedagogically, both for the demands it makes of readers' knowledge and for the questions it raises for teachers of literature around literary response. Teaching the poem at A-level for the first time twenty years ago, I realised that many of its highly specific cultural, historical and political allusions were not familiar to me or my pupils. We did not share Yeats' personal history, nor did we have immediate 
knowledge of modern Irish history or politics. Still, it is possible to deduce some facts about historical events from the lines of the poem - and as a pedagogical approach I might ask what can my pupils find in the poem that elaborates the historical event described? Once those details are exhausted, however, it becomes necessary for the teacher to make a judgement on what further information pupils need to consider in order to understand the poem, and how this can be accessed: what further texts should I select and present to my pupils, and with what rationale?

\section{Orientations to knowing, and to knowing 'Easter, 1916'}

The matter of literary response relative to 'Easter, 1916' is complicated in England because of the tacit assumption that response can be ahistorical, the pupil divorced from knowledge of the circumstances of the text's creation and with little space to articulate a perspective informed by their own social, cultural and historical context. Though these elements have been acknowledged in recently withdrawn GCSE and A-level specifications and assessment criteria, in the new curriculum and assessment regime they are much diminished. While examinations in Ireland overtly invite situated and historicised response, ours neutralise it. A striking Irish example is this:

Many of Eavan Boland's poems observe our violent history in a vivid and moving way; in spite of this, she does not take sides except to mourn the hurt. Discuss. (NCCA, 2010)

By contrast, questions around literature in our own specifications follow a rigid formula that abstracts textual production in the term 'presentation'. They ask, how does the author (or playwright) present a character (or theme)?, first in a decontextualized extract of the study text, and then with reference to the whole (see the new AQA GCSEs, for first examination in 2017, for example AQA, 2015). The influence of I.A. Richards' 'practical criticism' (1929) is strong, the assessment design assuming that literature can be appreciated with little metatextual knowledge. While one stated aim of the English curriculum is that pupils 'appreciate our rich and varied literary heritage', it is an intriguing and inconsistent orientation to literature in the context of the government's flirtation with the concept of 'core cultural knowledge' expounded by E.D.Hirsch (1988), as if core knowledge comprises contact with the prescribed study texts alone and does not extend to their individual complexities. Though it is no longer widely used in the examinations at GCSE level in England, 'Easter, 1916' is an example of a poem, typifying many, that has a distinctive sphere of allusion that could be considered unique 'core knowledge' at the level of an individual text (or indeed, to problematise further, as a focal text in a web of many related texts).

The pedagogical questions suggested by 'Easter, 1916' are elaborated again if we recognise that literary response is about readers - or pupils - as much as it is about texts. Responses in the literary classroom are often developed communally, a process which current curricular aims apparently complement in their attention to 'discussion in order to learn', where pupils have opportunities 'to elaborate and explain clearly their understanding and ideas'. Less sympathetic is the further aim that pupils become 'competent in the arts of speaking and listening', arts which explicitly comprise 'making formal presentations, demonstrating to others and participating in debate'. The list does not exclude literary analytic talk, but it is not recognised as a unique practice of spoken language with its own conventions and skills. The material presented in the rest of this paper explores the type of conversation unique to literary study, with a focus on 'Easter, 1916' and the demands of the poem already described. I recommend that readers of this article hear the poem in its entirety as context for the classroom conversation explored below, but here is the second stanza which is the focus for the exchange: 
That woman's days were spent

In ignorant good-will,

Her nights in argument

Until her voice grew shrill.

What voice more sweet than hers

When, young and beautiful,

She rode to harriers?

This man had kept a school

And rode our wingèd horse;

This other his helper and friend

Was coming into his force;

He might have won fame in the end,

So sensitive his nature seemed,

So daring and sweet his thought.

This other man I had dreamaned

A drunken, vainglorious lout.

He had done most bitter wrong

To some who are near my heart,

Yet I number him in the song;

$\mathrm{He}$, too, has resigned his part

In the casual comedy;

$\mathrm{He}$, too, has been changed in his turn,

Transformed utterly:

A terrible beauty is born.

\section{Knowing about and talking about 'Easter, 1916'}

The full research project from which this data is drawn will involve secondary phase schools in England, Ireland and Northern Ireland. The recording transcribed here was made in the first stage of classroom recording in Northern Ireland, with a post-16 A-level group in a girls' school led by a female teacher. All schools in the project have the option to use some common resources and techniques (Gordon, 2013) if they choose. This class heard their teacher read the poem's second stanza, and immediately followed it with this exchange. Bracketed items indicate indistinct words or phrases that were difficult to hear, each a guess at the actual utterance.

Teacher: ... so we aim to get the kind of listing of the kind of people involved now you were saying you thought it was Maud Gonne 
Student: I th- think it's like like a almost a metaphorical approach to like Ireland I (suppose)

Teacher: right

Student: on the whole kind of like a classic (mirror) image of Maud Gonne cos that's was always (unclear) always had it in somewhere in any poem so I think like he's actually like personifying Ireland as a woman

Teacher: that's very interesting because that was done at the time yeah

Student: hmm a lot

Teacher: lots of her iconography erm if we before I do tell you who I think this is and there are links as well to the same classic Maud Gonne (unclear) what other things would give you clues in there as as to who this is does anybody know who this is

Student: is it Countess Markievicz

Teacher: yeah it's Countess Markievicz what do you know about her

Student: erm I know that she was involved in the Easter Rising

Teacher: yeah

Student: and then she was arrested

Teacher: yeah

Student: and they wouldn't try her because she was a woman and that she was also involved in Daughters of Ireland

Teacher: good yeah and do you know how how Yeats knew her

Student: no was she was she not just from the same social circle of Belfast

Teacher: she was absolutely and she grew up

School bell rings

Teacher: she grew up as a child she was called Constance Gore-Booth so the doublebarrelled name Anglo Irish in beautiful Lissadell House in Sligo has anybody have any of you visited Lissadell it's open to the public again it was closed for a long time and Yeats spent a lot of time there and er she and her sister Eva again he was kind of fascinated by these two beautiful young women I'll show you a picture of her she went on to become involved in Irish revolutionary politics and actually took part in the Rising

Movement of teacher away from recorder, finding pictures, shows one

Clearly, pupils introduce details that are not presented overtly in the poem. One pupil offers a hypothesis (incorrect, as it turns out) that the woman described in the stanza is Yeats' friend and unrequited love, Maud Gonne. The hypothesis develops with reference to what one pupil proposes as 'kind of like a classic ... image' of her. To posit this interpretation, pupils must have knowledge of Maud Gonne as a prominent figure both in modern Irish history and in the social milieu of Yeats. The knowledge displayed here is sufficiently precise that pupils can attribute specific traits to her personality. One pupil proposes that in the figure of Gonne, Yeats is 'personifying Ireland as a woman', and the progress of the conversation indicates that other participants accept the proposal as reasonable. The structure of the conversation suggests a body of shared knowledge that endorses the hypothesis as possible and legitimate - 
even if it does eventually prove to be incorrect. The teacher opts to endorse the proposal too, echoing the pupil's comment that similar strategies of personification may be found in other poems by Yeats ('always had it somewhere in any poem'). That this initial endorsement is a considered pedagogic choice on the part of the teacher is evident in her next turn. Here she opens up the possibility that the woman is not Maud Gonne ('...before I do tell you who this is'), only for the pupil to offer instead 'Countess Markievicz'. At this point the teacher's move is to give an explicit request for the pupil to share 'what you know', the pupil responding with impressively precise detail. The reference to 'Daughters of Ireland', for example, is interesting given that the organisation Markievicz joined was founded by Maud Gonne, a detail consolidating the legitimacy of the earlier proposal in this field of knowledge. Here the pupil signals a depth of knowledge that comes from beyond the text, that we can speculate derives from social, cultural and historical knowledge likely to intersect with that of her peers and the teacher - even if they do not possess the same information exactly. Notice too that none of the participants request clarification of 'Daughters of Ireland'. The communal acceptance of the knowledge item and the progress of the exchange suggest shared knowledge that could not be accessed by readers unfamiliar with the context, and which in my experience was unknown to my pupils and I without desk-based study and very deliberate intent to find relevant contextualising detail. Even then, this exact connection - suggested in the apparently casual development of the conversation - is not one I have made or encountered in many years of considering the poem.

The same lesson also included interesting use of supporting visual texts, as indicated by the final line of the transcript above. In the continuing exchange, the teacher uses the visual prompt to activate students' knowledge of the rebellion and its protagonists, and specifically to consolidate understanding of Countess Markievizc's role as described in the poem's second stanza. The photo forms a bridge to the teacher's use of personal anecdote, which in turn clarifies for pupils the relationship between Markievizc's domestic realm and her role in the Rising:

There she is when she's younger (shows photograph) err when she was at Lissadell as a young woman you can see the size of her waist one of those Victorian tiny tiny waists and dressed as if for a ball so she was very much part of that ascendancy kind of culture in Ireland and these are some of the nam- the lines that he famously wrote about her the light of evening Lissadell great windows open to the south two girls in silk kimonos both beautiful one a gazelle and that was her that was that was Constance and when I was a child before Lissadell was closed and reopened her aunts were still living there and you could go and you could talk to them about her and one time my husband visited and being mischievous he said cos the aunts were awfully awfully (old by then?) they were very erm you know they were very (ladylike and everything) and he said do you think Constance ever shot anybody

Students: laughs

Teacher: and they went oh no no no Constance (unclear) things

Students: laughs

Teacher: she didn't actually carry arms whether she shot anybody or not (unclear) and here she is she's changed changed utterly

Students: Uhuh hah ! laughs

Teacher: what's that 
Student: that's the way images have (immense power / men's ?)

Teacher: that's right it's such a transformation into a uniform you know and she is commemorated beautifully in Sligo the fantastic kind of statue to her so this is the first name this is the first person.

The interplay of apparently informal verbal comment and attention to the image seems to emphasise key elements of Markievicz's biography relevant to this stanza of the poem. Use of the photo makes her more real, situating her in place, time and class (her dress locating her in an 'ascendancy kind of culture'). One pupil echoes an earlier contribution about personification of the nation, seeming to remark here on the 'immense power' of images. I think it is also significant that pupils are laughing, and enjoying the discussion, especially when the teacher riffs on the poem's refrain 'changed, changed utterly'. While the exchange seems to be expressed in casual mode rather than a stiff critical idiom, it arrives beautifully to the heart of the matter. The teacher's pun about changing clothes mirrors and thus underscores the transformation of each protagonist from relatively mundane existence to rebel and then to martyr. In the same mode the teacher also mentions a statue of Markievicz could that too be a subtle parallel with the poem's detail of hearts 'enchanted to a stone'?

\section{Conclusion: voices more sweet?}

The exchanges here represent just a small proportion of a single lesson. I couldn't say how far they are of typical literary pedagogy, if there is such a thing, or for that matter how far they typify any classroom talk. What can be gleaned, however, is the realisation that the knowledge pupils bring with them and which they deploy in their study of literature is not an easily quantifiable commodity: it will differ from classroom to classroom, one community to another, one country to the next. The text itself cannot be explained or understood according to one body of knowledge or a single prescribed package of 'core knowledge'. Furthermore, whatever knowledge pupils may have at their disposal, it takes unique skill on the part of teachers to elicit and guide collective responses towards anything approaching firm interpretation. Without stating an interpretation directly, this teacher gently guides her class to some valuable connections that provide a framework for their comprehension, a means to access an imposing and complex poem.

\section{References}

An impressive reading of 'Easter, 1916' by a Dublin schoolgirl is available via RTE (2015). A Poem for Ireland. http://apoemforireland.rte.ie/shortlist/easter-1916/

AQA (2015). GCSE English language (8700). AQA: Manchester

Department for Education (2014). National curriculum in England: English programmes of study. DfE: London

Gordon, J. (2013). A Pedagogy of Poetry. IoE Press: London

Hirsch, E.D. (1988). Cultural Literacy. Random House: New York 
NCCA (2010). Draft Guidelines for Teachers of English, Leaving Certificate English Syllabus. NCCA: Dublin

Richards, I.A. (1929). Practical Criticism: A Study of Literary Judgement. Routledge, Kegan and Paul: London 